\title{
EXPRESSION OF GAP JUNCTION PROTEIN CX43 IN DEVELOPING MICE EPIDERMIS
}

\author{
Zayed $A E^{1,3}$, Ahmed $Y A^{2}$, El-Hafez $E A^{1}$, Steger $K^{3}$. \\ ${ }^{1}$ Department of Anatomy and Histology, Faculty of Veterinary Medicine, \\ Assiut University, Assiut, Egypt \\ ${ }^{2}$ Department of Histology, Faculty of Veterinary Medicine, \\ South Valley University, Qena, Egypt \\ ${ }^{3}$ Department of Urology and Pediatric Urology, \\ University of Giessen, Giessen, Germany
}

\begin{abstract}
Gap junctions are intercellular channels responsible for the exchange of ions, second messengers and small metabolites between adjacent cells, and formed of connexin protein subunits. Although connexin 43 (Cx43) is commonly described to be expressed by keratinocytes, there is scanty studies that immuohistochemically followed the changes in the expression of CX43 associated with skin development.

The aim of the current study was to investigate the pattern of the expression of Cx43 in keratinocytes during different stages of skin development.

Mouse embryos (12, 14, 16, 18 and 20 days of gestation) were fixed in Bouin's or in $2.5 \%$ glutaraldehyde, and processed for paraffin or resin embedding. Skin was studied by the light and electron microscope to follow the morphological changes of the differentiated keratinocytes. Immunohistochemistry was performed on paraffin sections from skin of each embryonic age to explore the progress in the expression of Cx43 during different developmental times.
\end{abstract}


Zayed A. E. et al.,

Epidermis from 12 day-embryos was formed of 2 layers of undifferentiated epithelium, basal layer and periderm, with thickness about $10 \mu \mathrm{m}$. At 14 days of gestation, an intermediate layer appeared between the basal layer and periderm. The intermediate layer differentiated into stratum spinosum and stratum granulosum, and the periderm disappeared by day 16 of gestation. Stratification gradually increased with advanced ages and the skin layers were more prominent by 20 days of gestation, where the epidermal thickness reached about $50 \mu \mathrm{m}$. At 12 days of gestation, Cx43 expressed could not be detected, while by 14 days, it was seen in the intermediate and periderm layers, but the reaction was completely absent in the basal cell layer. The Cx43 expression intensity increased with skin development and by 20 days of gestation, the expression of Cx43 was restricted mostly into stratum spinosum and to less extend into stratum granulosum, but was completely absent from stratum basal and stratum corneum. The different pattern of Cx43 expression during skin development suggests that Cx43-mediated gap junction may play an important role in skin development.

Keywords: Gap junctions, Connexins, Skin

\section{INTRODUCTION}

Cellular communication is essential for homeostasis of different tissues and organs, and one common type of these communications is the gap junctions. Gap junctions are intercellular channels between opposing neighboring cells that selectively allow the passage of ions such as $\mathrm{K}^{+}$ and $\mathrm{Ca}^{2+}$, intracellular metabolites such as glucose and messenger molecules such as cAMP from the cytoplasm of one cell to the cytoplasm of another adjacent cell (Evans and Martin, 2002). Thus, the extend of cellular coupling and communication is related mostly to the gap 
junction permeability and its open or close states. Gap junction-based cellular communication is thought to participate in various biological functions. For example, in myocardium, they permit the rapid transfer of action potentials from one cell to another, ensuring harmonized contraction of the myocytes (Herve et al., 2008). In nervous tissue, they are involved in the development of the neurons (Sutor and Hagerty, 2005), normal growth and functional development of glia cells (Naus et al., 1999) and neurotransmission at electrical synapses (Kirichenko et al., 2009).

Gap junction channels are formed by clustering of integral membrane proteins known as connexins (Goodenough, 1974). The connexin protein family is encoded by at least 19 genes in rodents and 20 genes in human, and most tissues express more than one connexin type (Beyer et al., 1990). Connexin proteins are synthesized and integrated into membranes of the endoplasmic reticulum before transported into Golgi apparatus, where each sex connexins oligomerize into a hemichannel known as connexon which is carried within the Golgi vesicles and traffics along the microtubules to be inserted into the cell membrane (Thomas et al., 2005). Connexons from cell membrane of two adjacent cells interact to form a complete gap junction channel (Martin and Evans, 2004). To distinguish different members of connexins, a nomenclature system depends upon their molecular weight is widely used; for example connexin 43 (abbreviated to $\mathrm{Cx} 43$ ), represents the connexin protein of 43 kilodaltons ( $\mathrm{kDa}$ ), Cx26 refers to the isoform of $26 \mathrm{kDa}$, ect.

The skin is formed of two distinct tissues of different origin. The ectodermally derived epidermis and the underneath mesodermally derived dermis. The epidermis is composed of keratinocytes arranged in four 
separate layers or strata: basal layer or stratum basale, spinous layer or stratum spinosum, granular layer or stratum granulosum and the outermost cornified layer or stratum corneum. Keratinocytes in the stratum basal continuously proliferate and is pushed up differentiating into the cells in different layers. Proliferation of basal cell layers is associated with degeneration and shedding of the cornified cell layer (Eurell and Frappier, 2006).

Connexin 43, a connexin of 381 amino acid residues, is commonly expressed in different cell types. It was shown that $\mathrm{Cx} 43$ is expressed by keratinocytes in vitro (Brissette et al., 1991) and in vivo (Risek et al., 1992), and by hair follicles (Salomon et al., 1994).

Although the exact role of $\mathrm{Cx} 43$ in skin development is not well known, mutation in $\mathrm{Cx} 43$ results in some skin disorders emphasizing that Cx43 is essential for normal skin development (Mese et al., 2007). The aim of the current study was to understand the role of $\mathrm{Cx} 43$ in keratinocyte differentiation by following the changes in the expression of Cx43 in mice skin during deferent stages of embryonic development. Therefore, skin from mice of different ages was studied by a combination of light microscopy, electron microscopy and immunohistochemistry.

\section{MATERIALS AND METHODS}

\section{Reagents:}

Anti-Cx43 primary antibody was obtained from Zytomed (Berlin, Germany). Mouse anti-rabbit and rabbit anti-mouse immunoglobulins and mouse alkaline phosphatase anti-alkaline phosphatase (APAAP) antibody complex were purchased from DAKO (Carpinteria, CA, USA). Immunoreaction visualization kit was from HistoMark (KLP, USA) and primers were obtained from MWG (Ebersberg, Germany). 


\section{Animals:}

This study was conducted on 54 white mouse embryos aging 12, 14, 16, 18, 19 and 20 embryonic days; the presence of the vaginal plug was considered as day 0 of gestation. At least three embryos of each gestation stage were used for each experiment.

\section{Light microscopy:}

Embryos were fixed in Bouin's fixative for 24 hours, and then processed for paraffin embedding. Consecutive $5 \mu \mathrm{m}$ thick sections were cut from each block, mounted on superfrost slides (Menzel-Glaser, Germany) and dried for 24 hours at $37^{\circ} \mathrm{C}$. Sections were stained with the routine haematoxylin and eosin methods and examined with an ordinary microscope.

\section{Histomorphometric analysis of the skin:}

Thickness of the epidermis was measured using haematoxylin and eosin-stained paraffin sections from at least three different animals Images were captured with a digital camera linked to an Olympus BX 60 microscope and the measurements were made using 40x objective. Thickness measurements were taken between the dermo-epidermal junction and the uppermost point of the epidermis.

\section{Electron microscopy:}

Skin from mice of various developmental stages was cut into small pieces (approximately $2 \mathrm{~mm}$ ) and fixed in $2.5 \%$ glutaraldehyde/ $0.1 \mathrm{M}$ sodium cacodylate buffer, $\mathrm{pH} 7.4$ for at least 3 hours at room temperature. The fixed tissues were rinsed several times in cacodylate 
buffer, post-fixed in $1 \%$ osmium tetroxide, dehydrated in ascending grades of acetone $(50,70,80,90$ and 100\%) and embedded in Epon resin. Ultra-thin sections were cut with a diamond knife using Reichert OmU2 ultra- microtome. Sections were mounted on copper grids, stained with $5 \%$ aqueous solution of uranyl acetate for 10 minutes, washed with distilled water and stained with Reynold's lead citrate for 10 minutes. Sections were examined under a transmission electron microscope (TEM; Philips 300).

\section{Immunohistochemistry:}

Immunohistochemical staining for $\mathrm{Cx} 43$ on consecutive paraffin sections was carried. Briefly, sections in sodium citrate buffer ( $\mathrm{pH} \mathrm{6.0),}$ were incubated in a microwave at 1000 watts for 30 minutes. Endogenous peroxidases were inactivated by incubation of sections with $0.3 \%$ hydrogen peroxide $\left(\mathrm{H}_{2} \mathrm{O}_{2}\right)$ in methanol for 20 minutes. Non-specific reactions were blocked by treatment with $5 \%$ bovine serum albumin in phosphate buffered saline containing $10 \%$ fetal calf serum for at least 30 minutes at room temperature. Sections were incubated with the polyclonal anti-Cx43 primary antibody (1:250) over night at $4{ }^{\circ} \mathrm{C}$. Sections were incubated with mouse anti-rabbit immunoglobulin (1:50) as a secondary antibody, with rabbit-anti-mouse immunoglobulin (1:50) as a third antibody and then with mouse alkaline phosphatase antialkaline phosphatase (APAAP) antibody complex (1:100) for 30 minutes each. The immunoreactions were visualized using HistoMark kit. For each immunoreaction, control incubations were performed by substituting buffer for the primary antibody. The experiment was repeated at least twice. 


\section{Statistical analysis}

Statistical differences in thickness of the epidermis between groups of different ages of development were evaluated using one way ANOVA. The mean was taken from many sections obtained from at least three different animals at each developmental stage. For each comparison, a P-value of less than 0.05 was considered to be significant.

\section{RESULTS}

\section{Development of mouse skin:}

The surface epithelium (epidermis) of mouse embryos of days 1220 of gestation was investigated using hematoxylin- and eosin- stained paraffin sections (Fig. 1A-E), and the thickness of the epidermis was measured (Fig. 2).

At day 12, the developing epidermis appeared as a double-layered structure of an inner basal and outer periderm undifferentiated epithelium with thickness of $10.25 \pm 1.6$. At day 14 , stratification started, where the epidermis consisted of several layers, stratum basale and periderm, and stratum intermedium appeared between them. The thickness of the epidermis reached $17.1 \pm 2.82$. The epidermis of 16 day-mouse embryos was of $29.1 \pm 0.9$ thickness and the stratification increased. Interestingly, primary hair germs (early developmental structure of hair follicles) surrounded by condensation of dermal fibroblast could be identified in this stage. By day 18 of gestation, the stratum intermedium differentiated into stratum spinosum and stratum granulosum, and the thickness of the epidermis increased up to $44.2 \pm 1.9$. Dermal papillae were formed by aggregation of dermal fibroblasts and hair germs begun to elongate forming hair pegs. The formation of stratum corneum was evidenced by 
20 days of gestation, where the strata of the epidermis (especially stratum spinosum) were prominent and the thickness was maximized to be $55.7 \pm$ 4. Moreover, the fetal hair follicle was more prominent and acquired hair canal.

\section{Morphological evidence of presence of gap junctions between keratinocytes:}

The presence of gap junction in the mouse epidermis was studied with the electron microscopy (Fig. 3). Morphologically, the gap junction structures were not observed in the epidermis at 12 days of gestation. The intact gap junction structures were seen from 14 days of gestation, where most of the gap junctions were located in the attachment of the cells of the periderm and in the attachment between keratinocytes of the periderm and intermediate cell layers (later, stratum spinosum and stratum granulosum) with no obvious gap junctions between the cells of the stratum basale.

\section{Changes in the expression of $\mathrm{Cx} 43$ in developing mouse epidermis:}

The expression of $\mathrm{Cx} 43$ was immunohistologically detected in the epidermis of mouse embryos at different stages of gestation (Fig. 4A-D). At 12, all keratinocytes showed negative reaction to the $\mathrm{Cx} 43$ immunoglobulins (not shown). However, at 14 days, Cx43 expression was seen in the intermediate and periderm layers but the reaction was completely absent within the basal cell layer. The $\mathrm{Cx} 43$ expression intensity increased with skin development and by 20 days of gestation, the expression was restricted mostly to stratum spinosum and to less extend to stratum granulosum but was completely absent from stratum basal and stratum corneum. 


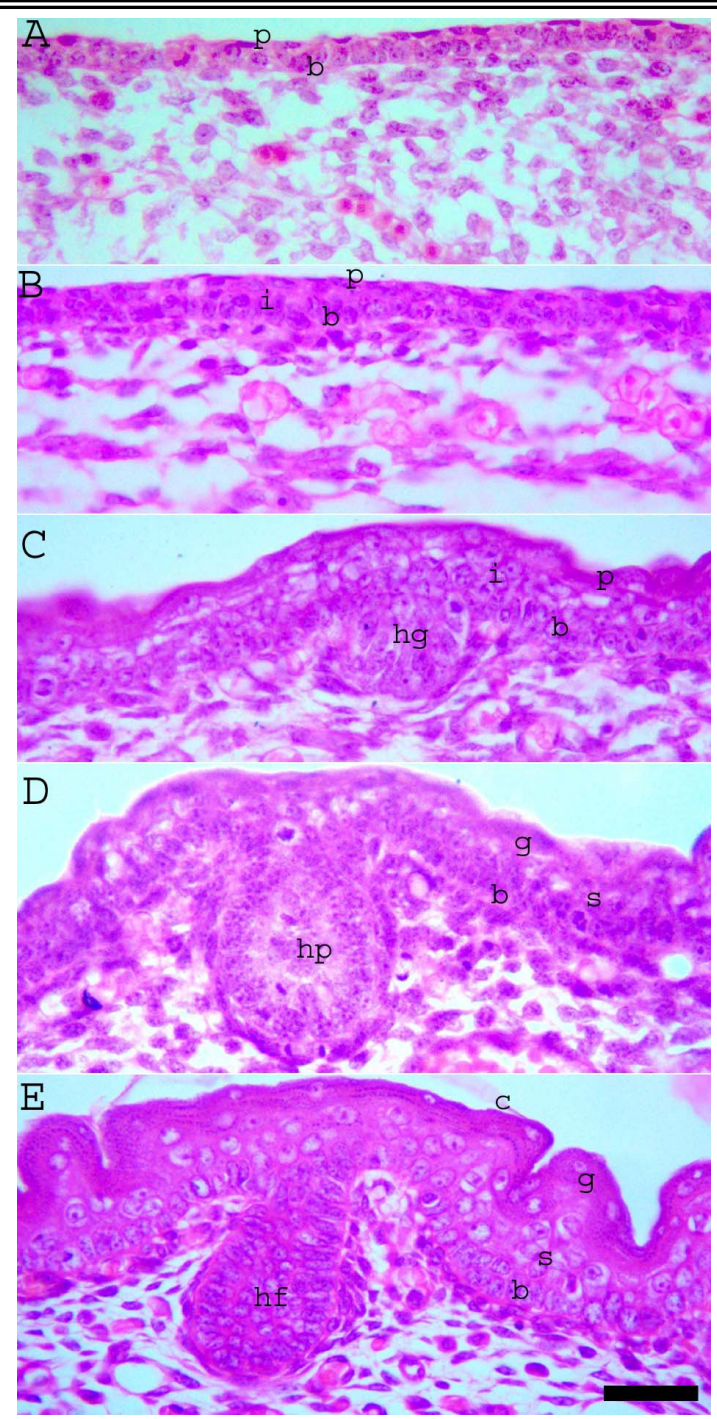

Fig. (1): Developmental changes of embryonic mouse skin.

Mouse embryos at various stages of development were embedded in paraffin, sectioned and stained with haematoxylin and eosin. A: Embryonic period of 12 days; double-layered of undifferentiated epithelium of stratum basale (b) and periderm (p). B: Embryonic period of 14 days; appearance of stratum intermedium (i) between stratum basal and periderm. C: Embryonic period of 16 days; appearance of primary hair germs (hg). D; Embryonic period of 18 days; differentiation of stratum intermedium into stratum spinosum (s) and stratum granulosum (g), and elongation of hair germs to form hair pegs (hp). E: Embryonic period of 20 days; stratum spinosum and stratum granulosum are more prominent. Hair follicles (hf) were formed. All parts have the same magnification; bar $=100 \mu \mathrm{m}$.

Kafrelsheikh Vet. Med. J. Vol. 7 No. 1 (2009) 


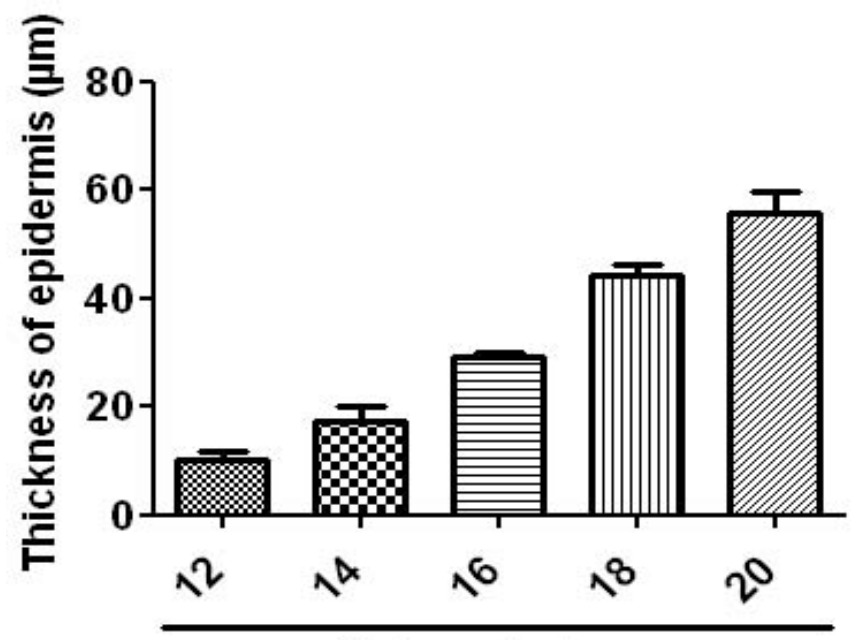

Embryonic day

Fig. (2): Developmental changes in the epidermal thickness of mouse embryos.

Thickness of the epidermis of mouse embryos at different stages of gestation was measured using hematoxylin and eosin- paraffin sections, and expressed as mean \pm SE. In comparison between each 2 subsequent stages of development, p value was < .05 .

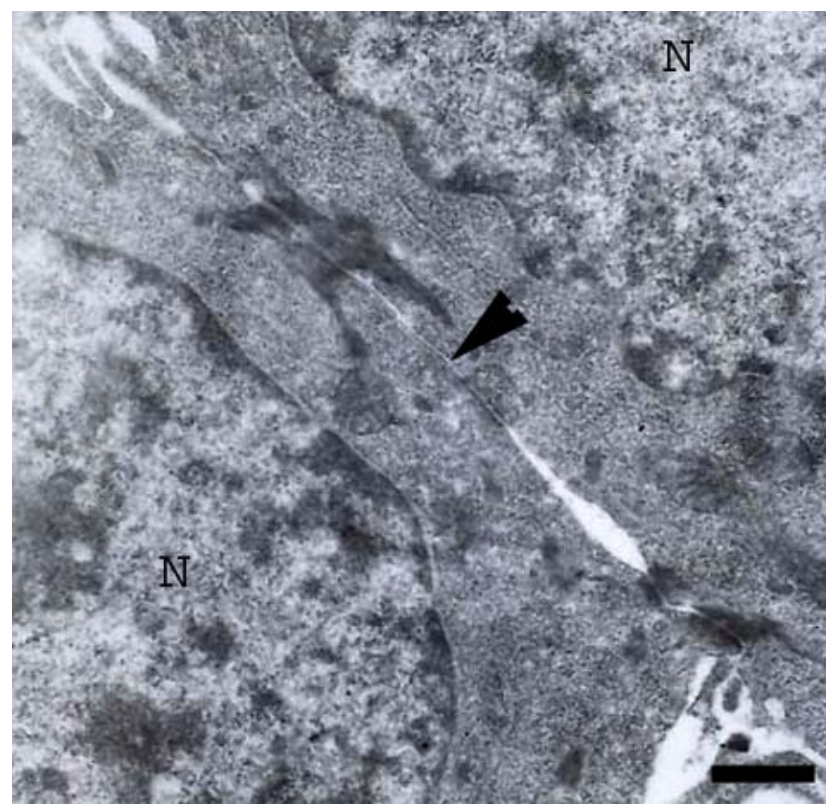

Fig. (3): Electron micrograph of epidermis from a 20 day- mouse embryo.

Gap junctional structures (arrowhead) was well developed between the cells of the stratum spinosum; bar $=2 \mu \mathrm{m}$.

Kafrelsheikh Vet. Med. J. Vol. 7 No. 1 (2009) 

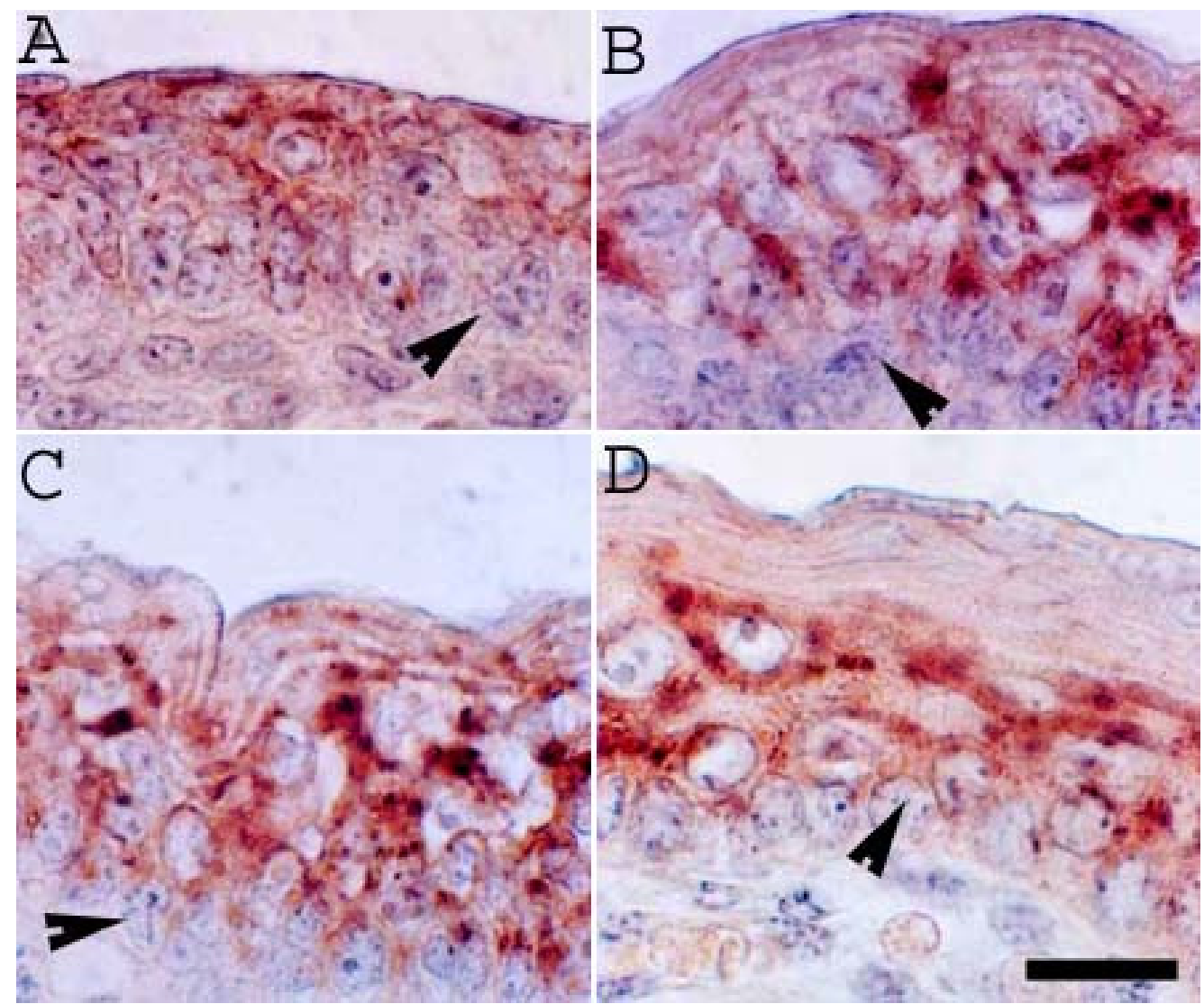

Fig. (4): Immunolocalization of $\mathrm{Cx43}$ in developing mouse epidermis.

Mouse embryos at different stages of development at 14 (A), 16 (B), 18 (C) and 20 (D) days were treated with $\mathrm{Cx} 43$ antibodies. The reaction was localized at the periderm (A), stratum intermedium (B), stratum spinosum and stratum granulosum (C, D) but was absent from the basal cell layers (arrowheads) in all developmental stages (A-D) and stratum corneum (D). All parts have the same magnification; bar $=30 \mu \mathrm{m}$. 


\section{DISCUSSION}

In the developing fetal mouse, the epidermis showed continuous changes during each studied developmental stage. At early stage (12 days of gestation), it appeared as 2 layers, the basal cell layer and periderm, and then an intermediate cell layer appeared where the stratification of the intermediate layer increased gradually by skin development with the disappearance of the periderm and formation of the nearly fully layered known structure of the skin by 20 days of gestation. The stages of development of mouse epidermis was similar to those described for human in a previous study (Arita et al., 2002).

Expression of $\mathrm{Cx} 43$ in the developing epidermis of mouse embryos was studied by the immunohistochemical technique. The current study showed that the pattern of $\mathrm{Cx} 43$ expression changed during different stages of gestation. It was expressed in the periderm and then intermediate cells (then in stratum spinosum and stratum granulosum) but never in the basal cell layer and its expression increased with skin development. The presence of connexin 43 in the basal cell layer is a matter of uncertainly between investigators. Some reports support our result that the basal cells of the mice epidermis lack the $\mathrm{Cx} 43$-formed gap junctions (Matic et al., 2002), but in human skin, $\mathrm{Cx} 43$ was described to be weekly expressed by the basal cell layer (Tada and Hashimoto, 1997). That may due to species variation between mouse and human keratinocytes. In addition, the electron microscopic studies revealed that the gap junctions also progressively advanced with skin development; the gap junction structures were evident in the periderm and intermediate zone and later in the strata spinosum and granulosum. These results suggest that $\mathrm{Cx} 43$, the main gap junction forming connexin 
in skin (Wiszniewski et al., 2000), may be closely related to the differentiation but not the proliferation of mouse keratinocytes as proliferation is related to the stem basal cells(Eurell and Frappier,2006), which never express $\mathrm{Cx} 43$ in mouse skin, or at lest show only week reaction in human skin. This suggestion is also supported by a previous study reported that the number of the $\mathrm{Cx} 43$ immunogold-labeled gap junction increased with skin differentiation (Arita et al., 2002). However, $\mathrm{Cx} 43$ is not the only protein forming the gap junctions in the skin. Other connexins were shown to be expressed in the epidermis and appears important for normal skin functions including proliferation of keratinocytes. Connexin 26 has been shown to be restrictly expressed in the outermost differentiated epidermal layer in later stages of development (Choudhry et al., 1997), Cx31.1 was present in the basal cell layer and Cx37 was found in spinous and granular cell layers in rodent epidermis (Goliger and Paul,1994). These connexin-mediated gap junctions are so important in the regulation of cell growth, differentiation and migration; as these processes are responsible for epidermis development and maintenance the normal functions of the skin (Richard, 2000).

In conclusion, the results shown in this study favors an important role of $\mathrm{Cx} 43$-mediated gap junction in the program of keratinocyte differentiation and skin stratification. Further studies on $\mathrm{Cx} 43$, including changes in gene expression during different stages of skin development, are required for understanding the junctional communication in skin.

\section{ACKNOWLEDGEMENTS}

The first author thanks Beatrix Frank and Barbara Fröhlick, Department of Urology and Pediatric Urology, for technical assistance. 


\section{REFERENCES}

- Arita, K., Akiyama, M., Tsuji, Y., McMillan, J. R., Eady, R. A. and Shimizu, H. (2002). "Changes in gap junction distribution and connexin expression pattern during human fetal skin development." J Histochem Cytochem 50(11): 1493-500.

- Beyer,E. C., Paul 'D. L. and Goodenough, D. A. (1990). "Connexin family of gap junction proteins." J Membr Biol 116: 187-194.

- Brissette, J. L., Kumar, N. M., Gilula, N. B. and Dotto, G. P. (1991). "The tumor promotor 12-O-tetradecanoyl phorbol-13-acetate and the ras oncogene modulate expression and phosphorylation of gap junction proteins." J Cell Biol 11: 5364-5371.

- Choudhry, R., Pitts, J. D. and Hodgins, M. B. (1997). "Changing patterns of gap junctional intercellular communication and connexin distribution in mouse epidermis and hair follicles during embryonic development." Dev Dyn 210(4): 417-30.

- Eurell, J. N. and Frappier, B. L. (2006). Dellmann's textbook of veterinary histology. Ames, Iowa, Blackwell Pub.

- Evans, W. H. and Martin, P. E. (2002). "Gap junctions: structure and function (Review)." Mol Membr Biol 19(2): 121-36.

- Goliger, J. A. and Paul, D. L. (1994). "Expression of gap junction proteins Cx26, Cx31.1, Cx37, and Cx43 in developing and mature rat epidermis." Dev Dyn 200(1): 1-13.

- Goodenough, D. (1974). "bulk isolation of mouse hepatocyte gap junctions. Characterization of the principal protein, connexin." J Cell Biol 61: 557-563. 
- Herve, J. C., Derangeon, M., Theveniau-Ruissy, M., Miquerol, L., Sarrouilhe, D. and Gros, D. (2008). "[Connexins and junctional channels. Roles in the spreading of cardiac electrical excitation and heart development]." Pathol Biol (Paris) 56(5): 334-41.

- Kirichenko, E. Y., Povilaitite, P. E. and Sukhov, A. G. (2009). "Role of gap junctions in local rhythmogenesis in cortical columns ". Neurosci Behav Physiol 39(2): 199-202.

- Martin, P. E. and Evans, W. H. (2004). "Incorporation of connexins into plasma membranes and gap junctions." Cardiovasc. Res. 62: 378-387.

- Matic, M., Evans, W. H., Brink, P. R. and Simon, M. (2002). "Epidermal stem cells do not communicate through gap junctions." J Invest Dermatol 118(1): 110-6.

- Mese, G., Richard, G. and White, T. W. (2007). "Gap junctions: basic structure and function." Journal of investigative dermatology 127: $2516-2524$.

- Naus, C. C., Bani-Yaghoub ‘M., Rushlow, W. and Bechberger, J. $\boldsymbol{F}$. (1999). "Consequences of impaired gap junctional communication in glial cells." Adv Exp Med Biol 468: 373-81.

- Richard, G. (2000). "Connexins: a connection with the skin." Exp Dermatol 9(2): 77-96.

- Risek, B., Klier, F .G. and Gilula, N. B. (1992). "Multiple gap junction genes are utilized during rat skin and hair development." Development 116(3): 639-51. 
- Salomon, D., Masgrau, E., Vischer, S., Ullrich, S., Dupont, E. and Sappino, P. (1994). "Tropography of connexins in human skin." J Invest Dermat 103: 240-247.

- Sutor, B. and Hagerty, T. (2005). "Involvement of gap junctions in the development of the neocortex." Biochim Biophys Acta 1719(12): 59-68.

- Tada, J. and Hashimoto, K. (1997). "Ultrastructural localization of gap junction protein connexin 43 in normal human skin, basal cell carcinoma, and squamous cell carcinoma." J Cutan Pathol 24(10): 628-35.

- Thomas, T., Jordan, K., Simek, J., Qing., S., Jedeszko., C., Walton, P. and Laird, W. D. (2005). "Mechanisms of Cx43 and Cx26 transport to the plasma membrane and gap junction regeneration." Journal of Cell Science 118: 4451-4462.

- Wiszniewski, L., Limat, A., Saurat, J. H., Meda, P. and Salomon, D. (2000). "Differential expression of connexins during stratification of human keratinocytes." J Invest Dermatol 115(2): 278-85. 